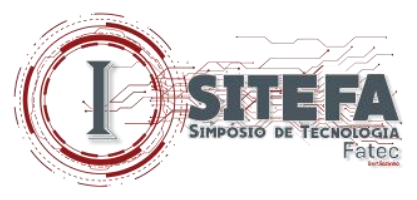

\title{
COMPORTAMENTO DE CONSUMO: A INFORMAÇÃO DOS PRODUTOS COMO RESPOSTA À LEALDADE DOS CONSUMIDORES SUSTENTÁVEIS
}

\section{CONSUMER BEHAVIOR: PRODUCT INFORMATION AS ANSWER TO SUSTAINABLE CONSUMER'S LOYALTY}

\author{
Profa. Dra. Claudia Rosa Acevedo - acevedocampanario@usp.br \\ Escola de Artes, Ciências e Humanidades da USP \\ Bruno Alves Catão - bruno.catao@gmail.com \\ Bacharel em Marketing pela Escola de Artes, Ciências e Humanidades da USP \\ Bruno Chiamura - bruno.chiamura@usp.br \\ Bacharel em Marketing pela Escola de Artes, Ciências e Humanidades da USP

\section{RESUMO}

Este artigo buscou relacionar as quatro etapas da lealdade do consumidor (nesta ordem: Lealdade Cognitiva, Lealdade Afetiva, Lealdade Conativa e de Lealdade Ação) com o consumo de produtos sustentáveis. Para tanto, realizou-se uma série de entrevistas com alunos da USP-Leste, visando aferir sua o quanto a sustentabilidade afeta seus hábitos de consumo. Esperava-se um viés nos resultados devido à presença do curso de Gestão Ambiental no campus, mas os resultados mostraram que, apesar de terem preferência por produtos sustentáveis e intenção de compra favorável a estes, suas ações ainda indicam um baixo nível de lealdade. Concluiu-se que, apesar de favoráveis ao consumo sustentável, a maior parte dos consumidores não chegou à fase da Lealdade Cognitiva, o que pode ocorrer devido à baixa representação de produtos sustentáveis no dia-a-dia do consumidor. Sendo a Lealdade Cognitiva o primeiro elo na corrente da lealdade de consumo, toda a ideia de um consumidor sustentável leal veio abaixo na amostra estudada.

Palavras-chave: Consumo Sustentável. Sustentabilidade. Comportamento do Consumidor. Lealdade de consumo.

\begin{abstract}
This paper sought to link the four phases of Consumer Loyalty (as in: Cognitive Loyalty, Affective Loyalty, Conative Loyalty and Action Loyalty) to the consumption of sustainable products. To that intent, a research was made among students of the Eastern campus of the University of Sao Paulo, aiming to ascertain how sustainability affected their consumption habits. A level of bias was expected, seeing that the Environmental Management course was located in that campus, but the results showed that, in spite of their preference for sustainable products and their favorable intentions towards consuming them, the actions of the students showed a low level of loyalty. We concluded that, even though the subjects were favorable to sustainable consumption, the majority
\end{abstract}




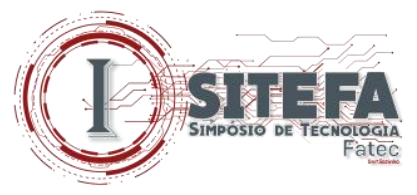

had still to reach Cognitive Loyalty, which may occur due to the low number of sustainable products in the consumers' routines. Being Cognitive Loyalty the first step to Consumer Loyalty, the idea of a loyal consumer of sustainable products crumbles.

Resumo em língua inglesa (obrigatório). Segue as mesmas indicações do resumo em língua vernácula e deve incluir as palavras chaves

Keywords: Sustainable consumption. Sustainability. Consumer Behavior. Consumer Loyalty.

\section{DOI:}

\section{INTRODUÇÃ̃o}

Os níveis atuais de consumo são vistos muitas vezes como desenfreados, levando à exaustão de recursos naturais, indo de encontro com um dos princípios de sustentabilidade, que versa sobre a importância de utilizar os recursos para suprir as necessidades de hoje e preservá-los para as futuras gerações (BRUNDTLAND, 1987).

Em resposta a isso, foi incluído na Agenda 21 Global, assinada na Rio 92, a prática do consumo sustentável, visando minimizar as consequências que consumo pode gerar, buscando observar tantos os impactos ambientais, quanto sociais desse ato. (MINISTÉRIO DO MEIO AMBIENTE, 2016).

Dessa forma, a preocupação com o meio ambiente, relacionando a sustentabilidade com a forma de consumo, é caracterizada como consumo sustentável. O consumo sustentável é um modo de vida que valoriza a responsabilidade ambiental como forma de preservar e manter um meio social com maior qualidade de vida. (CHERRIER, 2007; STOLE, MICHELETTI, BERLIN; 2010).

Boulding (1986) e Morgan (2000) são dois dos autores que postulam que a imagem que o consumidor tem de um produto/serviço influencia em como ele vê a marca e os processos envolvidos em sua produção, além de sua relação com o ambiente. Essa imagem, por sua vez, relaciona-se com a intenção de compra.

A visão de consumo sustentável se estende do ato de compra, podendo relacionar essa a ação com demais atitudes: reciclagem, adoção de comportamentos cuidadosos com o meio 


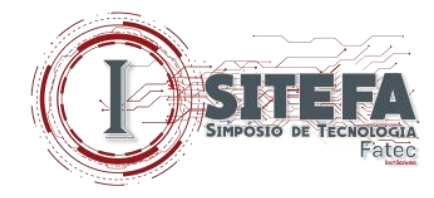

ambiente, redução da utilização de automóvel e o desperdício de materiais e de energia (SHAMDASANI; CHON-LIN; RICHMOND, 1993).

Produtos sustentáveis são capazes de influenciar a percepção de valor dos consumidores, e seu consumo pode ser visto como uma ação de cunho socioambiental já que preza por um bem de todos, inclusive do próprio cliente (LEITE, 2009).

Tendo como base esses dois constructos, consumo sustentável e percepção de valor, será verificado qual a influência na lealdade, sendo ela baseada pela estrutura Teórica de CogniçãoAfeto-Conação, conforme explica Oliver (1999), verificando até qual ponto o cliente está disposto a pagar para se manter dentro do grupo de consumidores sustentáveis.

A justificativa desta pesquisa é a de que o consumo sustentável vem ganhando destaque (GOMES, 2006) com a consciência da responsabilidade ambiental. Produtos sustentáveis agregam valor em cada etapa de sua produção, segundo Leite (2009), mas será que isto é suficiente para fidelizar o consumidor?

O objetivo geral desta pesquisa é avaliar a relação entre a percepção de valor de produtos de consumo sustentável, verificando a lealdade a esse estilo de consumo.

As hipóteses desta pesquisa são:

Figura 1 - Esquema de influência entre as variáveis

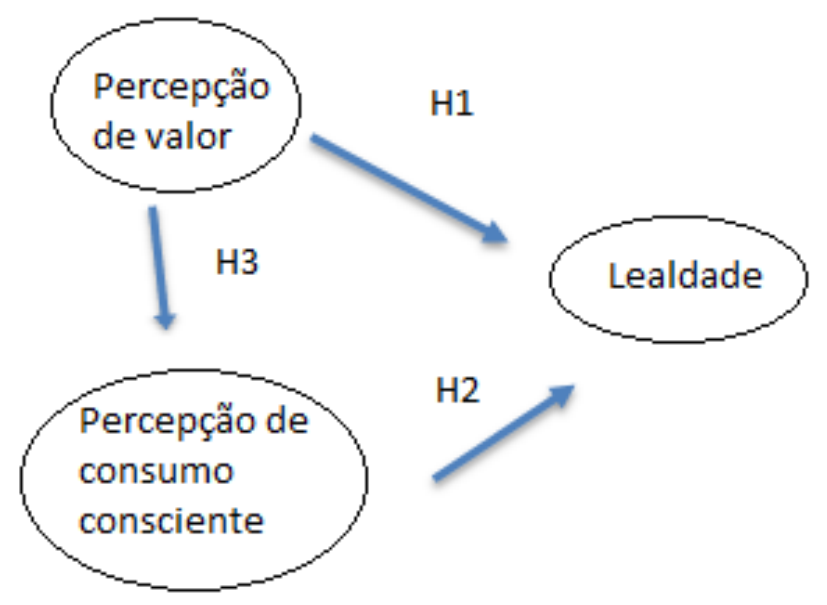

Fonte: elaborada pelos autores 


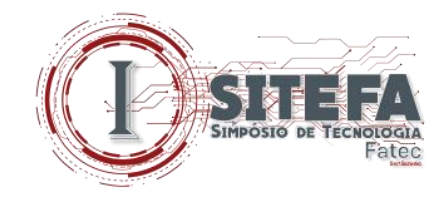

- $\quad$ H1: a percepção de valor influencia negativamente lealdade.

- $\quad \mathrm{H} 2$ : o consumo sustentável influencia positivamente a lealdade.

- $\quad$ H3: a percepção de valor é influenciada positivamente pela percepção de consumo sustentável.

Após a introdução do trabalho, este artigo apresenta a Revisão Bibliográfica, na qual são explorados os conceitos de Consumo Sustentável, Percepção de Valor e Lealdade; A Metodologia, na qual são apresentados os métodos da pesquisa; O Resultados, na qual os mesmos são discutidos; e, por fim, a Conclusão, na qual são discutidas as implicações deste trabalho.

\section{REVISÃO BIBLIOGRÁFICA}

O consumo sustentável ocorre quando se é levado em consideração os impactos, tanto positivos, quanto negativos que os produtos possuem, visando dessa forma estar dentro dos princípios da sustentabilidade. (DIÁLOGO AKATU, 2002).

Tais produtos são fabricados com matérias-primas renováveis, são recicláveis, biodegradáveis e duráveis, causando menos danos ao meio ambiente e utilizando seus recursos de maneira mais eficiente (OTTMAN, 2012).

É importante ressaltar que o consumo aborda outras questões que se relacionam ao ciclo de vida do produto, sendo: o pré-uso, a identificação com alguma causa ambiental, o uso, a manutenção dos produtos visando sua durabilidade e, por final, pós-uso, que visa à reciclagem/reutilização de tudo aquilo que não tem mais utilidade para o proprietário.

\subsection{Percepção de valor}

A percepção de valor de um produto de consumo sustentável está diretamente ligada à imagem do produto, buscando-se agregar a ele o bem-estar do consumo no ato da compra. Dessa forma, essa classe de produto de consumo sustentável pode ter como consequência o seu aumento no valor monetário, gerando um sacrifício por parte do cliente para adquiri-lo, sendo baseado na percepção de custo e benefício. (STANLEY; LASONDE, 1996). 


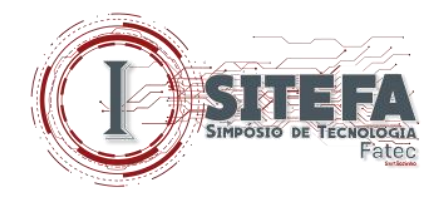

O conceito de valor é caracterizado pelo valor percebido pelo cliente e não muitas vezes como imaginado, pelo valor determinado pelo vendedor. O conceito de valor envolve uma avaliação do benefício, tendo-se um trade-off, entre o que se é comprado e o benefício gerado, por exemplo, envolvendo a questão monetária (BOLTON; DREW, 1991).

Assim, o "valor percebido é a avaliação geral do consumidor sobre a utilidade de um produto baseada nas percepções do que é recebido e do que é dado" (ZEITHAML, PARASURAMAN; BERRY, 1988, p. 14).

Para exemplificar a questão de percepção de valor, vamos utilizar alguns dos conceitos de Zeithaml, Parasuraman; Berry (1988, p. 13):

a) Valor é qualquer coisa que eu queira consumir de um produto: consumidores que enfatizam o benefício que recebem;

b) Valor é a qualidade que obtenho pelo preço pago: consumidores que entendem valor como uma troca entre o que é "dado" pelo que é "recebido" e a justiça nessa troca;

c) Valor é o que obtenho pelo que dou: consumidores que avaliam tudo o que recebem e o que dão em troca, ou seja, avaliam o valor como uma razão entre os atributos ponderados por suas avaliações, que é ponderado por suas avaliações.

Assim, ao obter um produto sustentável, o consumidor arca com um custo monetário maior, mas a imagem socioambiental que tem dele compensa o sacrifício, contanto que o consumidor seja um indivíduo consciente das questões de sustentabilidade.

Concluindo dessa forma que o nível de consciência sobre o consumo implica em atitudes favoráveis em relação à percepção de valor nos do produto de consumo sustentável. (TONI; LARENTIS; MATTIA, 2012).

\subsection{Lealdade}

A lealdade a um produto tem papel essencial no estudo presente, já que irá abordar uma classe específica de produtos, diante disso podemos partir da seguinte definição:

Dick e Basu (1994 apud TONI; LARENTIS; MATTIA, 2012), assim como McMullan e Gilmore (2003 apud TONI; LARENTIS; MATTIA, 2012), afirmam que a definição mais corriqueiramente aceita para a lealdade de clientes foi proposta por Jacoby \& Chestnut 


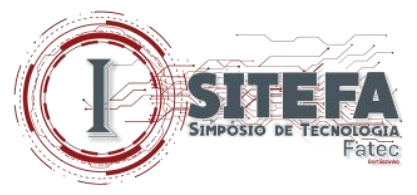

(1978 apud TONI; LARENTIS; MATTIA, 2012),que a consideram como o resultado do seu comportamento em relação à sua preferência por um produto em particular dentre um conjunto de produtos similares, por um período de tempo, decorrente de seu processo de avaliação e de decisão (TONI; LARENTIS; MATTIA, 2012).

O processo de avaliação e de decisão do consumo sustentável vai de encontro com o alto nível do produto, muitas vezes se gerando um sentimento, contentamento e até mesmo uma satisfação no ato da compra. Assim, quando analisado essas situações e sendo elas positivas, tende o cliente a se fidelizar ao produto (ZEITHAML; PARASURAMAN; BERRY, 1988).

Essa fidelização pode ser definida em quatro etapas, diante o estudo de Oliver (1999, p. 35) e idealizado por Fishbein e Ajzen (1975), conhecida como Teórica de Cognição-Afeto-Conação e a Lealdade de Ação. A lealdade está sendo analisada além da perspectiva comportamental, em outras palavras, a lealdade não deve ser vista apenas como um ato repetido de compra e sim como uma consequência comportamental do produto para com o cliente. Abaixo temos a explicação detalhada de cada etapa da lealdade:

Lealdade Cognitiva: marcada pela influência das informações sobre os atributos da marca disponíveis para o consumidor. Podendo definir uma marca/produto como superior às demais alternativas, relacionando a questão de preço, qualidade e benefícios do produto. Oliver (1999) afirma que esse conceito é baseado em uma experiência criada com o produto.

Lealdade Afetiva: como o próprio nome já deixa implícito, está relacionada ao afeto do consumidor, sendo analisada pelo gostar ou por uma imagem positiva transmitida pelo produto (OLIVER, 1999). Essa etapa da lealdade acaba por ser mais concreta que a lealdade cognitiva.

Lealdade Conativa: essa terceira etapa é influenciada pelas diversas ocorrências da etapa afetiva, se fortificando assim o afeto positivo com o produto (OLIVER; RUST; VARKI, 1997; OLIVER, 1999). A base dessa fase está no conceito de comprometimento com o produto, muito relacionada com a motivação, já que o ato de compra pode não ser realizado.

Além das etapas citadas acima, Oliver (1999) sugere uma quarta fase:

Lealdade de Ação: nessa etapa temos a junção de todas as etapas de lealdade citadas acima, no qual os estágios levam à ação de compra, tendo-se em vista a intenção de superar barreiras que impedem que a compra seja feita. 


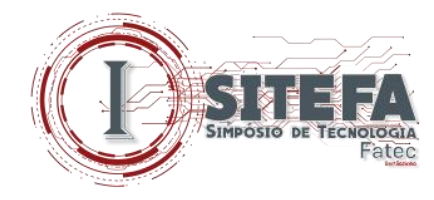

Assim, ao se completar as quatro etapas da lealdade, temos um cliente fiel ao consumo que lhe trará benefícios, vantagens e boas associações, sendo eles aqui citados como ações do consumo sustentável.

\section{METODOLOGIA}

Para a comprovação do estudo, foi elaborado um questionário para identificar à validade das hipóteses, tendo ele 46 perguntas e dividido em quatro etapas:

1) Questão analisando se o consumidor é caracterizado como sustentável, tendo dessa forma enraizado conceitos de valorização ao meio ambiente.

2) Análise de intenção de compra de produtos sustentáveis, validando assim o consumo propriamente dito.

3) Verifica a lealdade dos participantes, lembrando que um consumidor leal terá as quatro etapas da lealdade (cognitiva, afetiva, conativa e de ação).

4) A disposição de comprar produtos sustentáveis, tendo-se em mente a percepção de valor e o possível aumento do preço dos produtos.

Dentro de cada etapa, foi utilizado uma escala referente a cada constructo. Para consumo sustentável a escala utilizada foi idealizada por Ribeiro e Veiga (2010), que validou esse constructo, após a identificação do perfil do consumidor, é necessário avaliar sua intenção de compra, que será baseada na escala de Yoo e Donthu (2001). Verificando essas situações, foi validada a lealdade do consumidor, elaborada por Oliver (1999) e confirmando a informação obtida com a última escala: percepção de valor, construída por Enoki, Adum, Ferreira, Aureliano e Valdevino (2010), Silva (2012) e Bruner, Hensel e James (2005). Analisando dessa forma se o cliente se mantém leal mesmo diante do possível aumento do preço de produtos sustentáveis.

Partindo dessas quatro análises, podemos verificar a problemática do assunto nesse estudo abordado.

Para a análise estatística dos resultados, foi assumido para cada escala que todas as perguntas possuem o mesmo peso, podendo trabalhar todas as respostas com a mesma relevância e para melhor visualização das informações se utilizou a porcentagem referente a cada resposta, 


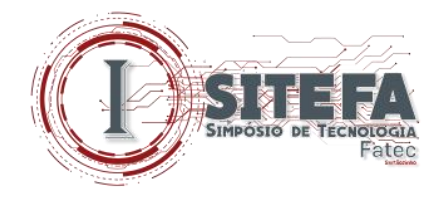

usando para demonstração os gráficos de radar, com a intenção de melhor visão de todas as informações obtidas.

Evidenciando e justificando a metodologia adotada, que o objetivo do projeto não será validar as escalas usadas e sim verificar sua relação entre si.

\section{RESULTADOS}

O questionário aplicado teve a participação de 284 consumidores $(n=284)$, sendo eles alunos da Universidade de São Paulo, campus Leste (EACH). É válido ressaltar que dentre dos cursos campus Leste, temos Gestão Ambiental, que pode influenciar na identificação do perfil do consumidor, caracterizando a maioria deles consumidores sustentáveis, porém tal análise não terá influência final no estudo, já que se trata apenas de um constructo analisado, dentre os quatro abordados.

Foram obtidas 13064 respostas, sendo elas divididas em cinco classes ordinais: nunca, quase nunca, às vezes, quase sempre e sempre.

A primeira análise foi sobre o perfil dos consumidores, sendo levantadas 5964 respostas e tendo os seguintes dados:

Figura 2 - Distribuição de respostas quanto à valorização dos produtos sustentáveis

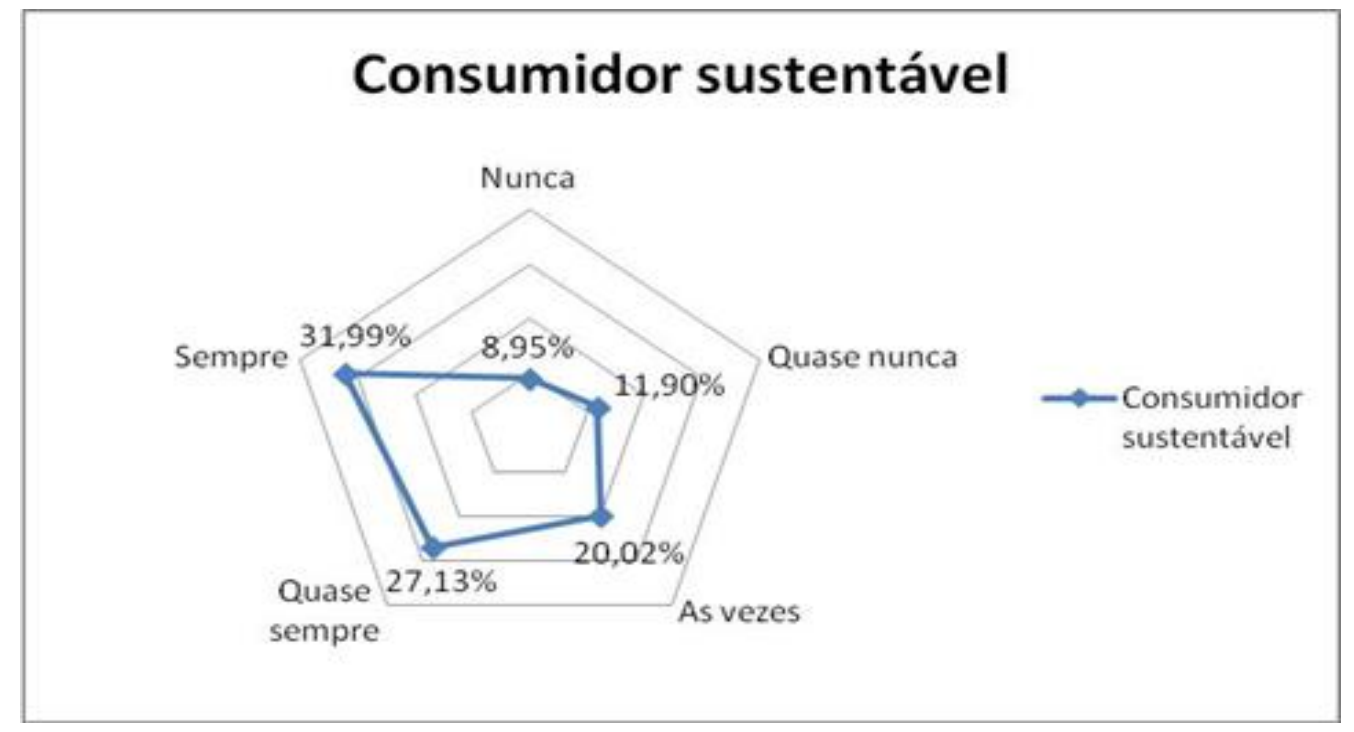

Fonte: elaborada pelos autores 


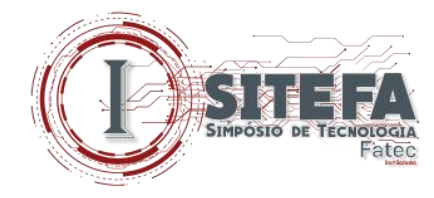

Concluindo então que 59,12\% dos entrevistados se encontra entre sempre ou quase sempre, significando que eles possuem uma atitude positiva ao consumo sustentável.

Após isso temos os resultados sobre intenção de compra, com 1136 respostas:

Gráfico 1 - intenção de compra de produtos sustentáveis

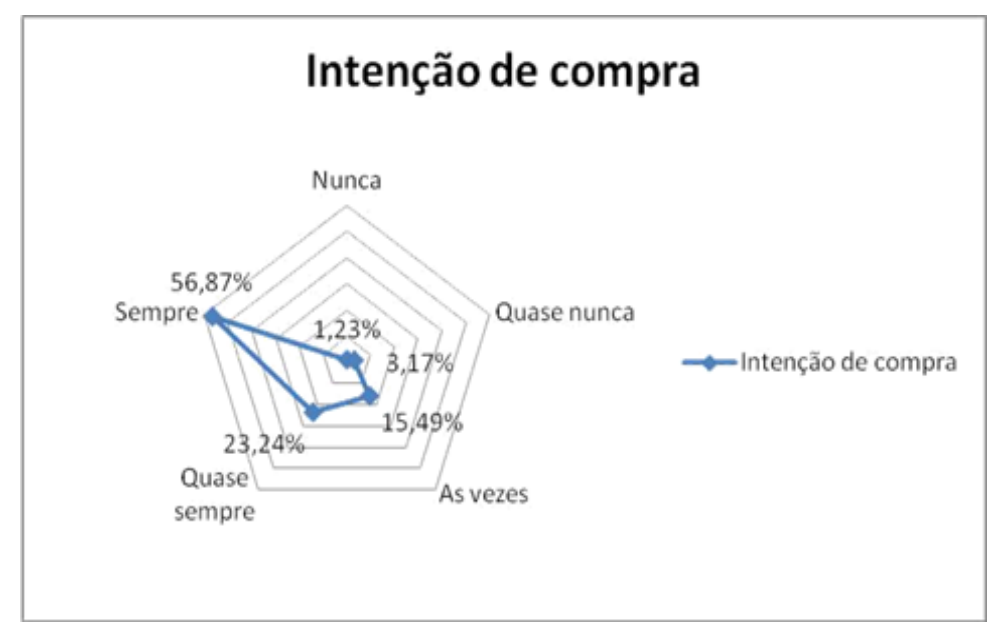

Fonte: elaborado pelos autores

Que comprova que os respondentes além de possuírem características de consumo sustentável tem a intenção de compra desta categoria, sendo também uma característica positiva para a análise do estudo.

A próxima etapa analisada foi a lealdade, que terá papel fundamental em nosso estudo. Dentro das 4544 respostas tivemos a seguinte situação:

Gráfico 2 - Gráfico de lealdade aos produtos sustentáveis

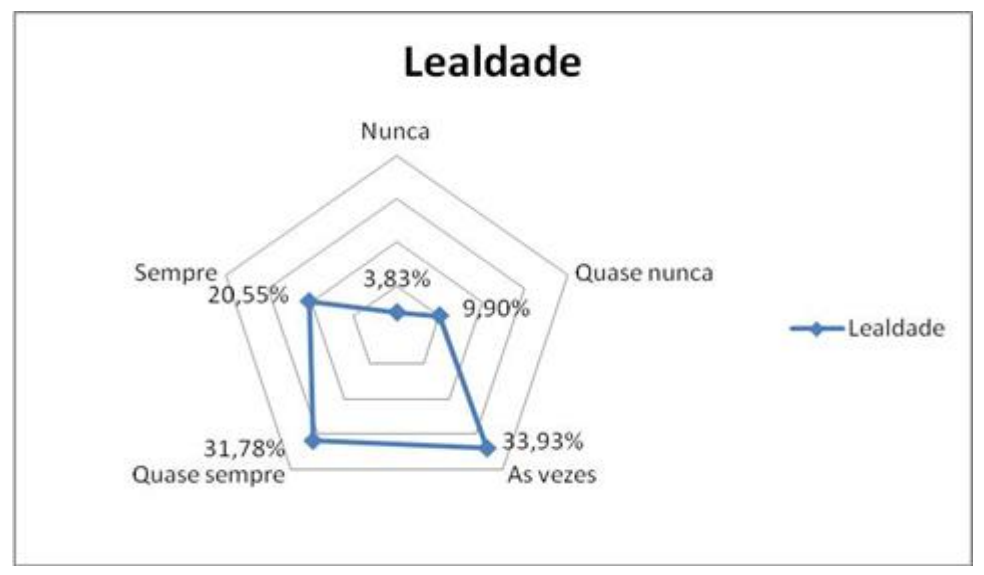




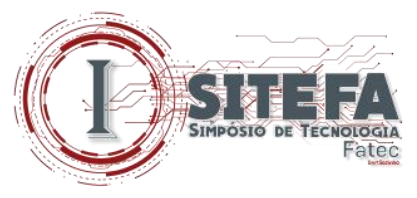

Fonte: elaborado pelos autores

Dessa forma, podemos concluir que os consumidores analisados de forma geral não são leais aos produtos sustentáveis, já que 33,93\% está classificado em uma classe mediana, porém pode se observar que grande parte destes consumidores $(52,33 \%)$ estão dentro da categoria quase sempre e sempre, podendo então supor que a situação que estamos analisando pode ser uma transição entre etapas, de não leal e para leal, tendo isso devido a importância que o meio ambiente vem ganhando no consumo como um todo (GOMES, 2006).

Para uma análise detalhada, vale ressaltar que a lealdade é dívida em quatro partes (cognitiva, afetiva, conativa e de ação). Tendo então os seguintes dados:

Gráfico 5a, 5b, 5c e 5d - resultados das quatro categorias de lealdade

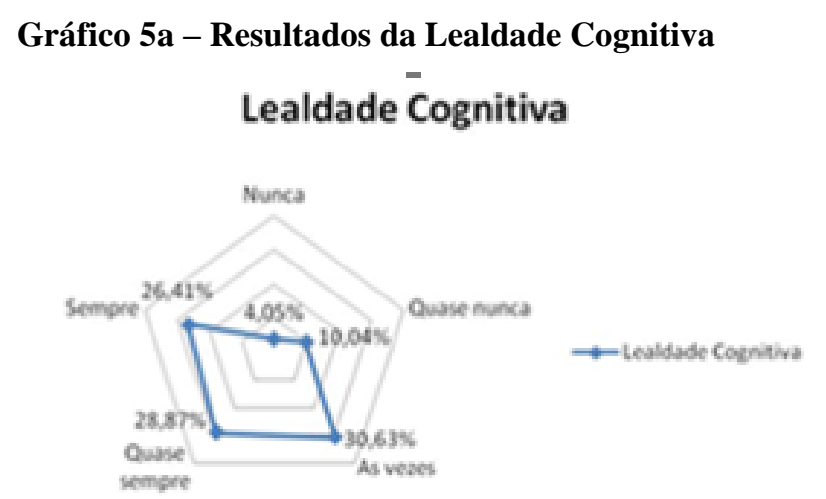

Fonte: elaborado pelos autores

Gráfico 5c - Resultados da Lealdade Conativa

Lealdade Conativa

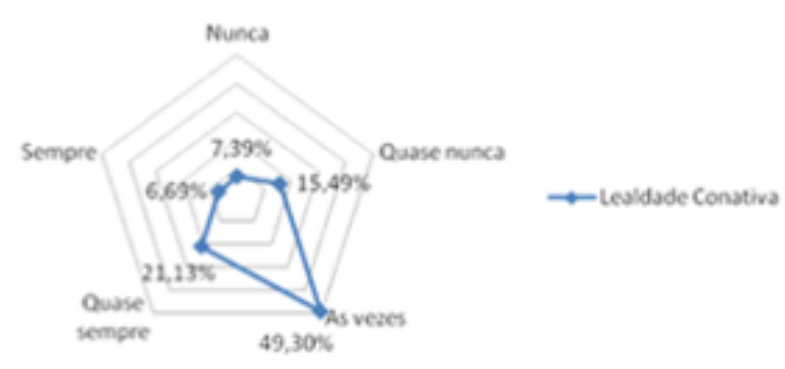

Fonte: elaborado pelos autores

\section{Gráfico 5b - Resultados da Lealdade Afetiva Lealdade Afetiva}

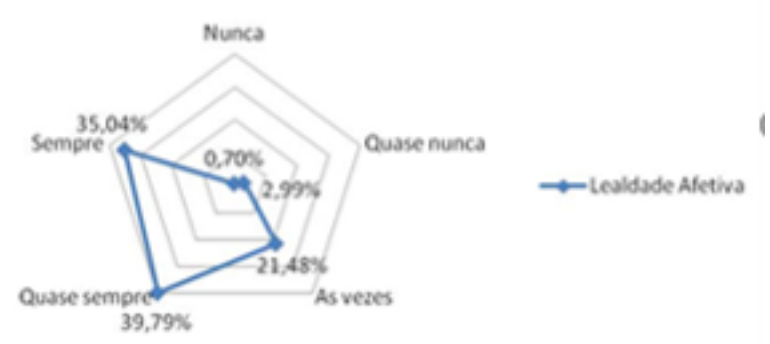

Fonte: elaborado pelos autores

Gráfico 5d - Resultados da Lealdade de Ação

Lealdade de Ação

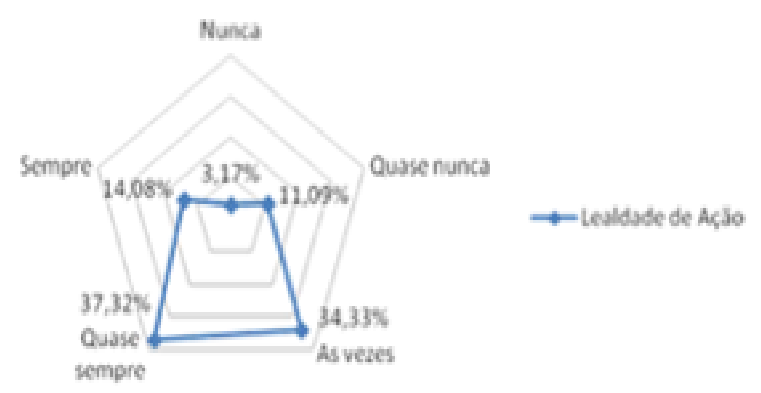

Fonte: elaborado pelos autores 


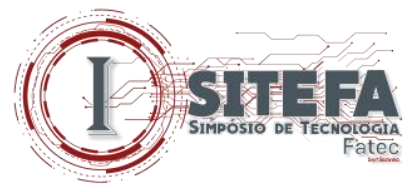

Analisando cada parte apresentada, podemos observar que na lealdade cognitiva, que se refere a crença que o consumidor tem sobre o produto, temos uma 30,63\% em uma classificação mediana, em contraposição temos $55,28 \%$ classificando os produtos sustentáveis de forma positiva. Seguindo, temos a lealdade afetiva, que cita a satisfação que estes cliente têm na compra e uso do produto, que apresenta que $74,83 \%$ se sentem bem por possuírem e utilizarem produtos da categoria sustentável. Na lealdade conativa, representada pela recompra de um produto, temos 49,30\% dos consumidores analisados em uma classificação mediana, mostrando que não necessariamente a recompra é realizada pelo cliente e por final, a lealdade de ação, referente a superação de possíveis barreiras para efetivação da compra, com 37,32\% admitindo que quase sempre consolidam a compra.

Finalizando temos os resultados obtidos sobre a percepção de valor, com 1420 respostas:

Gráfico 6 - percepção de valor sobre produtos sustentáveis

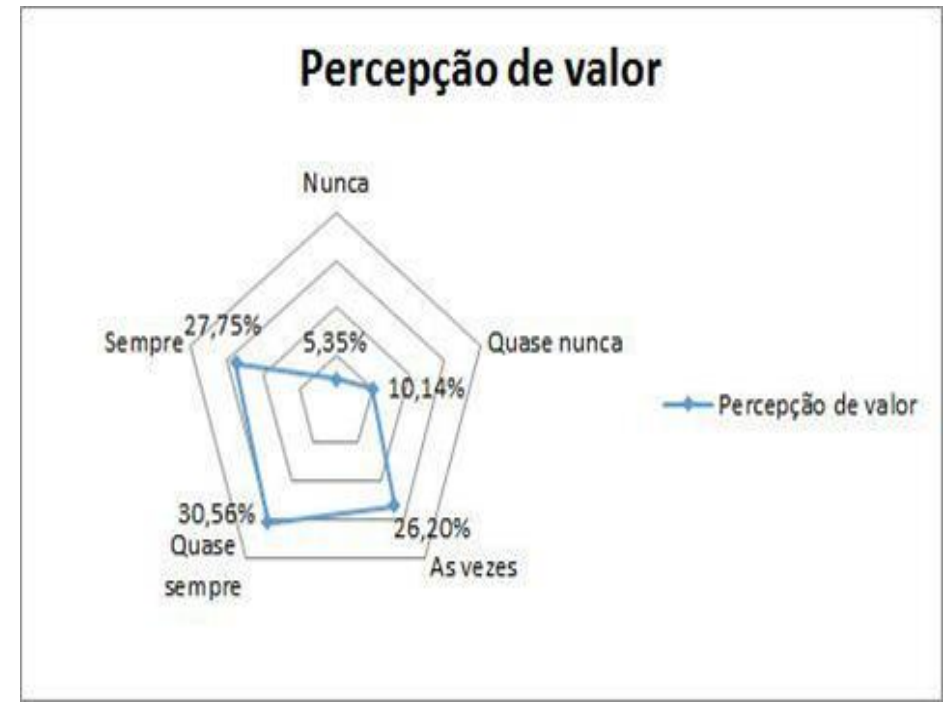

Fonte: elaborado pelos autores

Como observado, podemos ver que 58,31\% da amostra têm uma percepção de valor positiva sobre os produtos sustentáveis. 


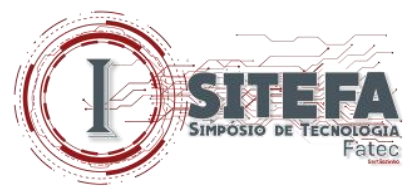

\section{CONCLUSÃO}

Com a análise de todos os resultados e utilizando como base as referências bibliográficas podemos chegar em um ponto decisivo no estudo, apresentando explicações e argumentações sobre cada tópico.

Os consumidores estudados podem ser classificados como praticantes do consumo sustentável, assim valorizam toda a cadeia produtiva, fator que pode ter sido influenciado devido a amostra ser realizada predominantemente dentro do campus da USP Leste, devido a presença de alunos de Gestão Ambiental.

Seguindo essa valorização temos a intenção de compra e percepção de valor, que demonstra que além da preocupação com o meio ambiente, eles se interessam por produtos de cunho sustentável e entendem que esses produtos tenham valor aumentado, porém esses fatores não necessariamente farão que a compra do produto seja efetuada, podendo ser vista como mais uma ação de reconhecimento em prol do meio ambiente.

A lealdade pode ser vista como um dos pontos primordiais nesse estudo. Verificando suas etapas, podemos concluir que a lealdade cognitiva, conativa e de ação, não possuíam respostas positivas, sendo elas as esperadas no estudo, demonstrando que os consumidores não são inteiramente leais a sua forma de consumo.

Detalhando a afirmação acima podemos propor que o ocorrido foi um efeito cascata. A lealdade cognitiva, que é a primeira fase da lealdade, não obteve valores positivos. Podendo afirmar que o cliente desconhece ds produtos sustentáveis, o que pode induzir a afirmar que não teve vivências como esse tipo de produto para se tornar assim fiel. Dessa forma, as últimas duas etapas, cognitiva e de ação, acabam por ser influenciadas, uma vez que os produtos sustentáveis não têm a mesma visibilidade que os comuns.

A etapa afetiva, que também está inclusa na lealdade, acaba por não ter uma influência significante, já que está diretamente relacionada ao afeto com os produtos sustentáveis. Fator que já foi confirmado analisando o perfil de consumidor e sua intenção de compra.

Uma cabível solução para essa questão seria melhor apresentação dos produtos sustentáveis, para que tomem espaço no mercado e sejam mais conhecidos para o consumo. Assim 


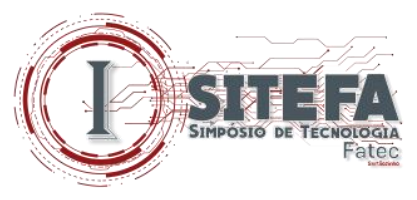

se aumentaria a possibilidade de conhecimento dos produtos e consequentemente a criação de experiência propriamente dita. Dessa forma, a lealdade conativa e de ação teriam maior influência para serem positivas e tornar um consumidor leal por inteiro.

Com o passar do tempo, como discutido no trabalho, o meio ambiente vem ganhando espaço, outro fator que irá auxiliar na inserção de produtos sustentáveis no mercado e possivelmente os torne mais comuns.

Assim, se dando a importância para informação e comunicação do produto com o cliente, com o passar do tempo, os consumidores estudados neste artigo possivelmente se tornarão mais sustentáveis e leais a sua forma de consumo.

\section{REFERÊNCIAS}

BOLTON R. N.; DREW J. H. A multistage model of consumers' assessment of service quality and value. Journal of Consumer Research, [S. 1.], v. 17, n. 4, p. 375- 384, 1991.

BOULDING, K. E. The image: knowledge in life and society. 6th printing. Ann Harbor: University of Michigan, 1986.

BRUNER, Gordon C.;HENSEL, Paul J.; JAMES, Karen E. Marketing Scales Handbook - A compilation of Multi-Item Measures for Consumer Behavior \& Advertising. V. IV.SouthWestern Educacional Pub, 2005.

CHERRIER, Hélène. Ethical consumption practices: co-production of self-expression and social recognition. Journal of Consumer Behaviour: An International Research Review, v. 6, n. 5, p. 321-335, 2007.

BRUNDTLAND, G. H. (Org.) Nosso futuro comum. Rio de Janeiro: FGV, 1987

STOLLE, Dietlind; MICHELETTI, Michele; BERLIN, Daniel. Young people and political consumerism. Fokus 10. En analys av ungas inflytande, 2010.

DIÁLOGO AKATU. Consumidor, o poder da consciência. São Paulo: Instituto Akatu, 2002.

ENOKI, Priscilla Azevedo; ADUM, Samir Hussain Nami; FERREIRA, Mariana Zanchetta; AURELIANO, Camila Aparecida; VALDEVINO, Sheila de Lima. Estratégias de marketing verde na percepção de compra dos consumidores na grande São Paulo. Jovens PesquisadoresMackenzie, v. 5, n. 1, 2010. 


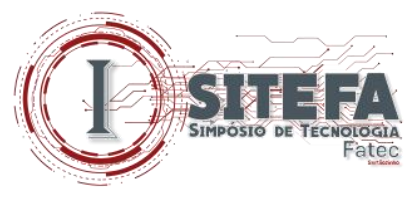

FISHBEIN, M., AJZEN, I. Belief, Attitude, Intention, and Behavior: An Introduction to Theory and Research. Reading, MA: Addison-Wesley, 1975.

GOMES, Daniela Vasconcellos. Educação para o consumo ético e sustentável. REMEA-Revista Eletrônica do Mestrado em Educação Ambiental, v. 16, 2006.

LEITE, P. R. Logística reversa: meio ambiente e competitividade. 2. ed. São Paulo: Pearson Prentice Hall, 2009.

MINISTÉRIO DO MEIO AMBIENTE. Consumo sustentável. Disponível em: <http://www.mma.gov.br/responsabilidade-socioambiental/producao-e-consumo sustentavel/conceitos/consumo-sustentavel> Acesso em: 25 out. 2016.

MORGAN, G. Imagens da organização: edição executiva. São Paulo: Atlas, 2000.

OLIVER, Richard L.; RUST, Roland T.; VARKI, Sajeev. Customer delight: foundations, findings, and managerial insight. Journal of retailing, v. 73, n. 3, p. 311-336, 1997.

OLIVER, R. L. Whence Consumer Loyalty? Journal of Marketing,[S. 1.], v. 63, n. 4, p. 33-44, Oct.1999. Special issue.

OTTMAN, J. A. As novas regras do marketing verde: estratégias, ferramentas e inspiração para um branding sustentável. São Paulo: Makron Books, 2012.

RIBEIRO, Juliane de Almeida; VEIGA, Ricardo Teixeira. Proposição de uma escala de consumo sustentável. 2011. 16 f. Tese (Doutorado) - Curso de Administração, Universidade Federal de Minas Gerais, Belo Horizonte, 2010.

SHAMDASANI, Prem; CHON-LIN, Gloria Ong; RICHMOND, Daleen. Exploring green consumers in an oriental culture: Role of personal and marketing mix factors. ACR North American Advances, 1993

SILVA, Catarina Estefânia de Albuquerque Morais da. Marketing Verde e o alinhamento empresa-consumidor. 2012. 55 f. Dissertação (Mestrado em Ciências Empresariais) Universidade Técnica de Lisboa - Instituto Superior de Economia e Gestão. Lisboa: 2012.

STANLEY, U. R.; LASONDE, K. M. The relationship between environmental issue involvement and environmentally-conscious behavior. Advances in Consumer Research, [S. 1.], v. 23, p. 183-188, 1996.

STOLLE, Dietlind; MICHELETTI, Michele; BERLIN, Daniel. Young people and political consumerism. Fokus 10. En analys av ungas inflytande, 2010. 


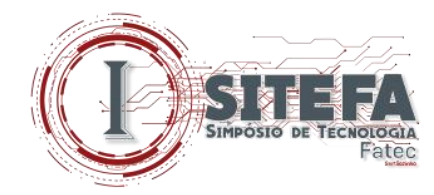

TONI, Deonir de; LARENTIS, Fabiano; MATTIA, Adilene. Consumo consciente, valor e lealdade em produtos ecologicamente corretos. 2012. 22 f. Tese (Doutorado) - Curso de Marketing, Universidade de Caxias do Sul, Caxias do Sul, 2012.

YOO, B.; DONTHU, N. Developing and validating a multidimensional consumer-based brand equity scale. Journal of Business Research, 52, 2001. p. 1-14.

ZEITHAML, Valarie A., PARASURAMAN, A. e BERRY, Leonard L.. Delivering Quality Service: balancing customer perceptions and expectations. New York: The Free Press, 1998. 